\title{
Multiscreen Technology Consumption and Dependence
}

\author{
Ana Lia Alves \\ School of Advertising and Marketing, Center for Innovation and Creativity, Brazil
}

Copyright $(2015$ by authors, all rights reserved. Authors agree that this article remains permanently open access under the terms of the Creative Commons Attribution License 4.0 International License

\begin{abstract}
Research and literature about internet and technology addiction has generated a great deal of attention in the past two decades. However, most studies in this literature focus on the relationships between internet addiction with social, educational, and physical variables but not many addressing the link with emotional variables such as anxiety. With the increase adoption of mobile technologies and the increase of multiple device usage, there is a need to understand how multiscreen dependence influences these emotional variables. This paper uses an exploratory methodology that included a focus group and semi-structure interviews to explore these relationships and provide a better understanding of the multiscreen usage effect on consumer sentiment and dependence behaviour.
\end{abstract}

Keywords Multi-screen Consumption, Technology Dependence, Internet Addiction, Anxiety

\section{Introduction}

The global multiscreen consumer uses around seven hours of screen media daily with $47 \%$ of the time spent on $(35 \%)$ smartphones and (12\%) tablets ([1] Millward Brown, 2014). Concerned with this trend, US companies plan to increase multi-screen campaign expenditure by $149 \%$ in the next three years (ANA and Nielsen, 2013). As digital connectivity expands, so has the complexity of marketing through a cluttered environment of multiscreen usage becoming increasingly difficult to capture consumer's attention. On the other hand, consumers are also impacted by this 'have it all, share it all, anywhere, at any time' [2] mentality changing behaviour and social norms. The ability to create an integrated experience that may flow from fix to portable devices and vice-versa provides consumers a sense of continuous connectedness increasing one's anxiety levels. This in turn, if frequent and recurrent, may create dependence and possibly addiction.

The literature on the addiction-technology relationship is vast and has attracted the interest from many research areas ([3]Murali and George, 2007; [4]Shapira et al., 2003; [5]Young, 1998). Although the importance of research on internet addiction has grown, most studies in this literature focus on the relationships between internet addiction with social, educational, and physical variables. But, there is little research addressing the association of internet addiction with emotional variables such as anxiety ([6]Akin and Iskender, 2011; [7]Razieh et al., 2012). Further, with the increase adoption of mobile technologies and the increase of multiple device usage, there is a need to understand how multiscreen consumption influences these emotional variables. Thus, the aim of this paper is to explore these relationships and provide a better understanding of the influence of multiscreen technology on consumer anxiety.

\section{Literature Background}

In today's social environment, one's individual routine is filled with electronic device interactions, such as smartphones, tablets, laptops, and computers. People constantly engage in various forms of activities, but according to a recent study by Millward Brown (2014), not all devices are used for the same purpose or intent. While laptops and PCs are considered 'productive tools', tablets are used mostly for amusement and entertainment on-the-go. Smartphones on the other hand, are the 'do-it-all' devices that allow consumers to constantly connect, check on social status, and/or finish work on-the-go. A typically global user spends around $47 \%$ of the screen time consumption daily on mobile devices but this is not a dedicated consumption as people's attention is divided between devices with $35 \%$ of screen interactions being simultaneous. In a similar study, Ipsos (2012) demonstrate that the main motive for simultaneous screen usage was to socialize online (e.g. to continue the conversation about a TV show or sport's game they have watched).

Although prior research shows that greater use of technology, in particular internet, is associated with declines in the size of social circle, loneliness ([8]Yang, 2001), lower self- esteem and life satisfaction ([9]Ko, Yen, Chen, Chen, and Yen, 2005), sensation seeking ([10]Lin and Tsai, 2002), poor mental health ([11]Yang, 2001; [12]Young and Rogers, 1998), and low family function ([13]Armstrong, Phillips, and Saling, 2000), multiscreen usage can increase socialization by facilitating online community engagement. This, however, has a negative effect as continuous online engagement can create dependence that may enhance anxiety 
and stress levels. In this line of though, this research proposes that the increase of multiscreen devices and simultaneous usage increases anxiety levels and puts restrains on the individuals' social relationships rather than making individuals more socially connected. This social disconnection is a symptom of many addictive behaviours.

According to Goodman ([14]1990) addiction can be defined as sum of dependence plus compulsion. Dependence involves positive reinforcement; an attempt to achieve a pleasurable internal state via gratification of needs. On the other hand compulsion corresponds to a negative reinforcement paradigm or an attempt to evade or avoid an unpleasurable emotional state (e.g. anxiety, grief, guilt, shame, rage). Thus, while multiscreen usage cause dependence by facilitating gratification, it also may create negative reinforcement as anxiety to be connected and to respond to social pressure increases when one is 'always' available. Prior research has defined anxiety as an internal state that involves creating expectations that aim quick accomplishment ([15]Chua, Chen, and Wong, 1999). In terms of consumption, anxiety is usually related to the moment of satisfying a gratification need that despite of its external consequences (e.g. lack of social engagement) must be fulfilled immediately or with a quick turn-around. This study looks at anxiety not only as a variable within the addiction perspective but as an emotion that drives multiscreen consumption.

\section{Exploratory Research}

\section{Method and Sample}

Two exploratory studies were undertaken as basis for a larger project now in progress. An online focus group followed by twelve semi-structured interviews that were conducted in June 2014. The focus group was a convenience sample of twelve Facebook consumers. These people represented a broad spectrum of the population in terms of technology usage levels, occupation, and age ranging from 25 to 60 years old. But all of them reported to be regular users of multi-screen devices, including PC, Laptop, Smartphone, and Tablet. Subjects were highly animated about the topic. The closed Facebook group discussion lasted about three days. Interviews were conducted with the same pool of participants as the focus group. Interviews typically lasted about an hour and were conducted over the phone. The interviews were recorded and then transcribed. Findings of this research are discussed next.

\section{Focus Group}

A focus group discussion guide was developed prior to the commencement of the group while the semi-structured interview questions were developed after analysis of focus group data. These discussion guides contained a series of discussion points and suggested questions which began with more general multiscreen usage questions, (e.g., "How many devices you use every day and what do you mainly use them for?") to more specific situational questions (e.g., "I'd like you to think of a situation where you were not supposed to use these devices due to tasks of your everyday routine. How anxious do you get to know what is happening on social media? How much attention can you give to your task during those situations? Have you experience any problems from the use of these devices? If so, can you explain what happened?"), and dependence usage (e.g., "Thinking about multiscreen constant usage, do you think that the amount of engagement you have with multiple devices can become an addiction? If so, what would be happening that would indicate its occurrence?"). The discussion was allowed to move beyond the specific topic raised in the focussing question to allow new concepts and themes to emerge.

\section{Findings}

In our study, two broad areas of discussion were examined and the findings are provided below. First, we discuss consumer sentiments toward the contextual and deliver of the devices connection. Then, the anxiety related to the consumption of multiple devices and its impact on social behaviour and individual routine is explored.

Consumer sentiments toward their routine associated with any of the four devices are crucial and taken as an extension of their own body.

"I cannot stay a part from my mobile. I have to be connected to be part; I have to share my moments with my network to feel alive. If I forget my phone at home, I feel like something from my body is missing" (subject 8).

This statement brings a perspective of how the dynamic of the relationship requires an extension from the virtual presence usage, which impacted how consumer's sentiments have been built lately. There seems to be a connection that involves the feeling of accomplishment, physiological need of attachment to the device, and the aim to feel connected to others. Further, individuals not only felt the need to be connected with the device but also to the benefits that its use may bring to them. The expectation to receive, share, or interact with the web or social media creates great amount of anxiety as reflected by these following statements:

"The use of multi devices, mainly mobile, makes me very anxious to check any reply on everything that I post on Facebook and from content that I create on other social platforms" (subject 3)

"I cannot wait anymore. I want instant replies and if something is not of my interest or makes me bored in that moment, I search in other devices a way to distract or entertain myself, even if it is for a few minutes" (subject 11).

"I just can't go more than an hour without checking what is happening in the world or with my friends. I stay connected all the time I can and I only logout when I am tired, or if I must do something" (subject 2). 


\begin{abstract}
"When there wasn't any of this, I enjoyed things around me much more. I was resilient to embrace this connected world. Today I see that there is no return from being connected and it is hard to control the desire to check my status all the time. I feel very distracted and the world surrounding me became less interesting than that of the screen" (subject 5).
\end{abstract}

People recognized without been aided that they are more likely to be connected to people away from them, then the others near physically by them. Life values seem to be more attractive to achieve reach by sharing the life among several people than the present ones. Although these people seem concerned with the fact that they are not fully enjoying their surroundings, they showed to be a lot less interested about what is 'real' to them. Their concerns are just not as strong or attractive as the notifications, alerts and happenings from their digital presence. They also seem to have lost general attention to what is 'outside' of the screens being distracted all the time. Finally, while they lack attention for the external environment, participants demonstrated to be more concerned about fulfilling their own needs and interests making it harder to grab their attention even with relevant things that would be initially appealing to them. If they pay attention, it must capture their interested in a glance to be worth to keep them hold. But even so, it will not hold them on for too long as they are anxious for the next big thing.

\section{Conclusions}

Multiscreen usage is a new consumer trend and has gain the interest from many marketing practitioners and academics. In this exploratory study, we have sought to understand how multiscreen usage, technology dependence and anxiety are related. By conducting an exploratory survey that included an online focus group and semi-structured interviews, we were able to outline some important aspects that concern users of multi devices. It seems clear that digital connectedness is a one-way trip. Once you are in there is no way back. The easy access to multiple devices that connects individuals to the digital world 24/7, makes it nearly impossible for individuals to disconnect. The offer is simply too attractive making the 'real' environment seem less interesting. The results shown here also reveal that people are changing their abstraction level by becoming short term oriented rather than having long term expectations. This in turn, influences how people see and relate to slow responses to their actions and often causing frustration and disappointment. Future research should continue to investigate the link between multiscreen usage and emotional variables. Also, another venue for research is to further investigate dependence versus compulsion in this context and how it is affected by the growth of multiscreen consumption.

\section{REFERENCES}

[1] Akin, A., and Iskender, M. (2011). Internet addiction and depression, anxiety and stress. International online journal of educational sciences, 3(1), 138-148.

[2] Armstrong, L., Phillips, J. G., and Saling, L. L. (2000). Potential determinants of heavier internet usage. International Journal of Human-Computer Studies, 53(4), $537-550$.

[3] Association of National Advertisers (ANA) and Nielsen (October 2013). ANA and Nielsen Study Reveals Multi-Screen Advertising to Rise Dramatically. Retrieved from

http://www.nielsen.com/us/en/press-room/2013/ana-and-niel sen-studyreveals-multi-screen-advertising-to-rise.html

[4] Chua, S.L., Chen, D.T., and Wong, A.F.L (1999). Computer Anxiety and Its Correlates: a Meta-Analysis. Computers in Human Behavior, (15)5, pp. 609-623.

[5] Goodman, A. (1990). Addiction: definition and implications. British journal of addiction, 85(11), 1403-1408.

[6] Ipsos (2012). The new Multi-Screen World: understanding cross-platform consumer behaviour. Retrieved from $\mathrm{http} / / /$ www.ipsos.fr/sites/default/files/attachments/multiscree nworld_final2.pdf

[7] Ko, C.-H., Yen, J.-Y., Chen, C.-C., Chen, S.-H., and Yen, C.-F. (2005). Gender differences and related factors affecting online gaming addiction among Taiwanese adolescents. The Journal of nervous and mental disease, 193(4), 273-277.

[8] Lin, S. S., and Tsai, C.-C. (2002). Sensation seeking and internet dependence of Taiwanese high school adolescents. Computers in human behavior, 18(4), 411-426.

[9] Milward Brown (2014). Adreaction: marketing in a multiscreen world. Retrieved from http://www.millwardbrown.com/adreaction/2014/report/Mill ward-Brown_AdReaction-2014_Global.pdf

[10] Murali, V., and George, S. (2007). Lost online: an overview of internet addiction. Advances in Psychiatric Treatment, 13(1), 24-30.

[11] Razieh, J., Ghasempoor, A., Ajdari, Z., and Sadeghigooghari, N. (2012). The relationship between Internet addiction and anxiety in the universities students. Interdisciplinary Journal of Contemporary Research in Business, 4(1), 942-949.

[12] Shapira, N. A., Lessig, M. C., Goldsmith, T. D., Szabo, S. T., Lazoritz, M., Gold, M. S., and Stein, D. J. (2003). Problematic internet use: proposed classification and diagnostic criteria. Depression and anxiety, 17(4), 207-216.

[13] Yang, C. K., 2001. Sociopsychiatric characteristics of adolescents who use computers to excess. Acta Psychiatrica Scandinavica, 104, 217-222.

[14] Young, K. S. (1998). Internet addiction: The emergence of a new clinical disorder. CyberPsychology \& Behavior, 1(3), 237-244.

[15] Young, K. S., \& Rogers, R. C., 1998. The relationship between depression and internet addiction. CyberPsychology \& Behavior, 1, 25-28. 